\title{
$\mathrm{PH} 92$
}

\section{Narrando (100) paisajes culturales de España}

La incorporación de los paisajes culturales a las políticas de patrimonio es relativamente reciente. Se trata de bienes culturales sometidos al dinamismo y complejidad de la escala territorial, de manera que su salvaguarda se ha mostrado especialmente sensible a la apreciación que suscitan entre la ciudadanía. El proyecto Narrando Paisajes, a través de la web www.100paisajes.es, invita a conocer qué es un paisaje cultural mediante una muestra representativa de estos bienes culturales en España.

Grupo de Investigación Paisaje Cultural, ETSA, U. Politécnica de Madrid

URL de la contribución <www.iaph.es/revistaph/index.php/revistaph/article/view/3959>

Esta selección de cien paisajes ha sido elaborada por el Instituto del Patrimonio Cultural de España en colaboración con las comunidades autónomas, atendiendo a criterios de diversidad cultural y tipológica. El diseño de la plataforma facilita una experiencia de descubrimiento y aprendizaje a través de navegación cartográfica y visualización de material audiovisual, textual, fotográfico y sonoro. Además, la plataforma opera como vehículo entre el ámbito científico y la sociedad, permitiendo una comunicación bidireccional.

\section{Mapa y narración}

Al acceder a la plataforma, un mapa del territorio nacional en el que se geolocaliza una selección de cien paisajes culturales es el elemento base que da inicio a la navegación y permite dos opciones: en primer lugar proporciona una visión de conjunto y permite al usuario ir definiendo el contenido activando o desactivando capas; en segundo lugar actúa como interfaz sobre la que se indexa información adicional, dando acceso a una explicación detallada de cada uno de los cien paisajes.

Sobre el mapa principal se han diseñado tres niveles de interacción con información espacial. El primero consiste en un desplegable que permite mostrar y ocultar los paisajes culturales según su carácter dominante (con cuatro categorías diferenciadas por colores: paisajes agrícolas, ganaderos y forestales; simbólicos; industriales; y urbanos, históricos y defensivos). El segundo nivel permite al usuario activar o desactivar paisajes según la presencia de una serie de valores asociados que los caracterizan, más allá de su carácter domi- nante. $Y$ un tercero que permite visualizar varios sistemas de articulación espacial de nivel supra-territorial, como espacios naturales, ríos, caminos históricos o vías pecuarias.

Además se permite la navegación vertical. Atraído por los iconos de localización de cada paisaje, el usuario puede hacer zoom de aproximación y acceder a un mapa de mayor detalle, de manera similar a plataformas de uso popular. A partir de una cierta escala, cuando la pantalla ya enmarca el territorio ocupado por el paisaje en cuestión, el mapa gráfico se transforma en fotografía
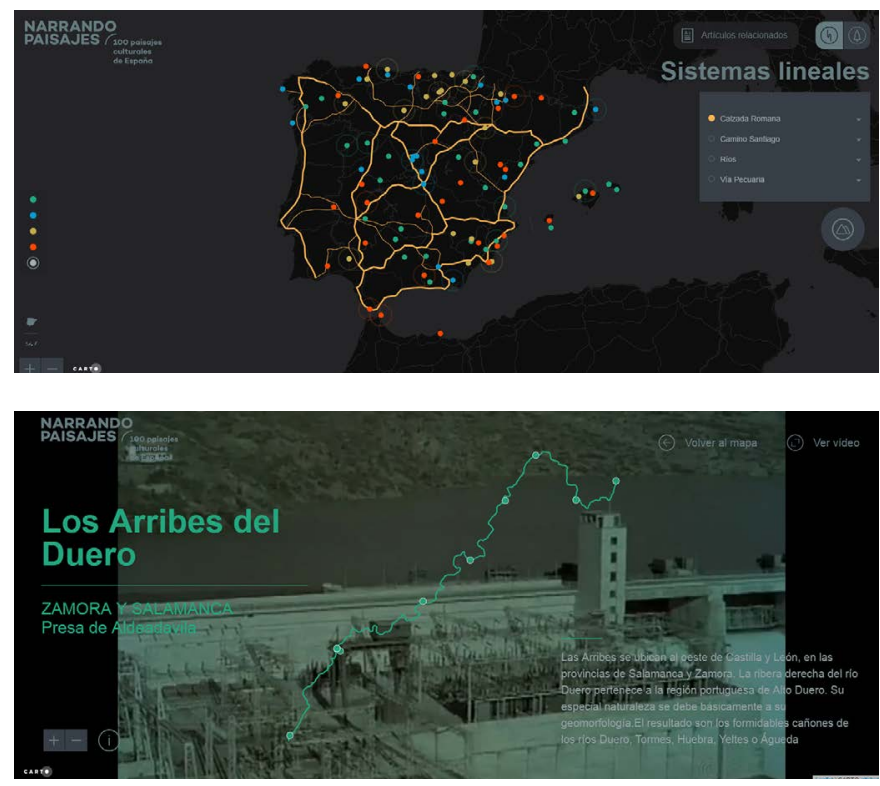

Web proyecto Narrando Paisajes http://www.100paisajes.es 
aérea, permitiendo advertir a vista de pájaro las estructuras, formas y elementos que lo componen.

Hay una relación esencial entre la usabilidad y la base conceptual de la plataforma. Los iconos de georreferenciación, junto a las capas de información adicional, favorecen una manera sencilla de interactuar con el mapa, pero lo suficientemente desarrollada como para explicitar la complejidad y dinamismo característicos de estos bienes culturales de dimensión territorial.

El acceso a la información de cada paisaje desde el mapa principal es intuitivo: pulsando sobre los puntos que aparecen geolocalizados. La mayoría de los paisajes se exponen con una ficha en la que aparece una imagen, un texto descriptivo de sus valores, una ortofoto, sus valores asociados y una bibliografía específica.

Entre todos ellos se han seleccionado veinticinco para ser narrados de manera más amplia y compleja. La elección se ha hecho en base a criterios de singularidad, bien por sus atributos o bien por su pertenencia a la Lista de Patrimonio Mundial.

Estas narraciones pretenden trasmitir que la percepción de los individuos en el paisaje es de un valor patrimonial esencial. Para tratar este aspecto se ha empleado información inmersiva, definida como aquella que expone cualidades perceptivas no cuantificables y que, en cierto modo, permite al usuario sumergirse en el lugar. El material que se muestra en estos casos incluye: fotografías y vídeos grabados mediante dron, teléfonos móviles o cámaras de gran angular y extraídos de redes sociales; grabaciones históricas de archivos; o incluso películas que tienen como escenario un determinado paisaje.

\section{Conclusiones}

El desarrollo de Internet y de las tecnologías de la información ha permitido establecer relaciones entre grandes cantidades de datos aparentemente distintos con los que el usuario puede interactuar y construir su propia secuencia en la navegación. Conceptos como el de hipertexto e hipermedio han llevado a redefinir otros como el de enciclopedia y el de atlas. En la proforma Narrando Paisajes, el mapa es, simultáneamente, meca- nismo narrativo e interfaz a la que se indexan los cien paisajes culturales. Es decir, el usuario puede acceder directamente a la información de un paisaje y luego pasar a estudiar el conjunto, o acceder a un segundo paisaje. De esta forma, se presenta como un medio de adquisición de conocimiento abierto y sin jerarquía, siendo la propia interacción del usuario con la plataforma lo que le permite formar un relato que le conduzca a deducir ideas propias.

Un aspecto innovador del proyecto es que no solo la información gráfica y textual es fuente de conocimiento: la usabilidad también contribuyen al aprendizaje. Por un lado, la navegación por el mapa y la posibilidad de activar o desactivar capas de información geográfica hace intuir al usuario que estamos ante un bien cultural dinámico y complejo. Por otro, el material audiovisual activa la percepción del paisaje cultural y, desde ahí, su apreciación por el usuario. Se trata, en definitiva, de una estrategia de comunicación innovadora basada en la inmersión y la experiencia que resultan indispensables para su valoración social.

\section{DATOS DEL PROYECTO}

Proyecto cofinanciado por el Programa de fomento de la cultura científica, tecnológica y de la innovación de la FECYT (FCT-2015-9585), y desarrollado en el marco del Plan Nacional de Paisaje Cultural del Instituto del Patrimonio Cultural de España.

Equipo de investigación: Francisco Arques (investigador principal), Javier Ruiz Sánchez, Rodrigo de la O, Nicolás Mariné, David Escudero

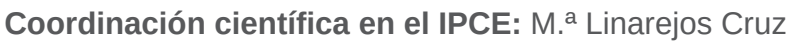

Comité científico: Juan Miguel Hernández León, Miguel Ángel Aníbarro, Concha Lapayese, Ana Belén Berrocal, Marian Leboreiro, Jorge Bernabeu

Becarios de investigación: Sofía Romeo, Zhang Yingle, Lucia Sayans, Silvia Ayala

Publicación: Subdirección General del Instituto del Patrimonio Cultural de España (2015) 100 Paisajes Culturales en España. Madrid: Ministerio de Educación, Cultura y Deporte 